\title{
A single-end directional relaying scheme for double-circuit transmission line using fuzzy expert system
}

\author{
A. Naresh $\operatorname{Kumar}^{1}\left(\mathbb{D} \cdot\right.$ Ch. Sanjay² $\cdot$ M. Chakravarthy ${ }^{3}$
}

Received: 16 October 2019 / Accepted: 24 January 2020 / Published online: 14 February 2020

(c) The Author(s) 2020

\begin{abstract}
The faults occurring in different sections are difficult to identify using the traditional techniques. This paper investigates a fuzzy expert system for directional relaying, classification, and location of faults in double-circuit transmission lines. The current magnitudes measured at only one terminal of the double-circuit transmission line are used to compute discreet Fourier coefficients. Thus, this scheme does not involve any communication channel. The presented fuzzy expert system is achieved from the structure of MAMDANI system in LabVIEW software. Test case studies show the effectiveness of the presented scheme. The simulation results attest that the directional relaying, classification, and location estimation is very accurate. This scheme is adaptive to the change of fault location, fault resistance, fault inception angle, and fault type.
\end{abstract}

Keywords Currents $\cdot$ Faults $\cdot$ Fuzzy system

\section{Introduction}

The transmission line is indeed a very important part of the power system. The transmission lines are exposed to vagaries of atmospheric conditions, thus most prone to a fault. It causes a disturbance in the continuity of power supply. To maintain the steadiness of the power network under all operating conditions, it is required to build up a sufficient protection system as possible still in action. The protection system must apply a practical algorithm in clearing faults within pre-defined time. Early fault detection is required to minimize the incidences severity of power system damage. Therefore, it is vital to design a quick, reliable, and complete protection network for different shunt fault cases and also against direction relaying, classification and location of faults in double-circuit line. Hitherto, several techniques have been reported in the area of protection in transmission line to study the directional relaying under different faults.

A. Naresh Kumar

ankamnaresh29@gmail.com

1 Department of EEE, Institute of Aeronautical Engineering, Hyderabad, India

2 Department of EEE, GITAM University, Hyderabad, India

3 Department of EEE, Vasavi College of Engineering, Hyderabad, India
Much work has been done to focus how faults can affect the power system [1-3]. Numerous strategies have proposed to determine directional relaying in transmission lines [4-6]. Researchers have explained technique to classify and locate transmission line faults in [7-9]. The protection techniques $[10,11,12]$ have been used the fault currents only. The protection procedures $[13,14,15]$ have been explored the one end data only. The scheme in [16] uses only fundamental currents of one end bus discriminate section faults (directional relaying). The classification and location of shunt fault by considering fundamental component of currents in transmission line from one end has been widely studied in [17]. A comprehensive study of protection methodology for transmission line is described in [18]. The methodologies in the literature [1-17] did not provide the discrimination, classification, and location of shunt faults in double-circuit three-phase transmission (DC3PT) line.

Authors discuss the directional relaying schemes [19, 20] for the DC3PT lines, classification scheme [21, 22] for shunt faults in the DC3PT lines, the fault location schemes [23, 24] under shunt faults for the DC3PT lines which have been demonstrated. Previous work [25] has shown the artificial neural network (ANN) technique for DC3PT line that provides direction relaying, classification, and location of faults. Nonetheless, the above methodologies have some difficulties, especially inaccuracies, which require training data and more computation time. Fuzzy expert system (FES) does 
not require training and needs IF-THEN rules only. FES in fault location lessens computational complexities. The FES approach played a vital job in the fault directional relaying, classification, and location measurements. The FES design concepts [26-28] has been explained. The FES [29-32] has been used in Lab VIEW. The FES designing is used for protection of transmission lines [33-35], but these do not protected the DC3PT faults. Fault classification and location using FES in three-phase circuit lines are explained in [36]. More details of FES implementation for direction relaying are found in [37]. The study of [38] suggested the FES algorithm for direction relaying, classification, and location in six-phase transmission line.

To the best of our knowledge, to date, no one has conducted this type of analysis in DC3PT line using FES method. In this paper, a new fault directional relaying, classification, and location procedure is introduced for DC3PT line based on FES and fundamental frequency component of currents. Unlike most of the past contributions in the literature [4-9], the proposed FES approach is independent of other end information. Summary of proposed work contributions is explained as:

1. Analyzing the fault behavior in two sections.

2. Development of FES-based protection methods for directional relaying, classification, and location in DC3PT.

3. Avoid the use of contact network for sending and receiving terminals.

4. Less computational complexity.

5. Detection of the faults effectively.

6. Improvement of the accuracy, \% error, and reach setting.

The contributions of this paper can be summarized as follows. In the section "Introduction", we briefly present the related work and novelty. The section "System studied" focuses on the line modeling, configuration, and simulation of shunt faults. The section "Proposed FES-based scheme" presents the details of the proposed FES approaches. In the section "Response of the proposed scheme", we devote a discussion on the proposed FES approach performance and the obtained simulation results. Finally, the section "Conclusions remarks" concludes this paper.

\section{System studied}

In this work, a $400 \mathrm{kV}, 50 \mathrm{~Hz}, 200 \mathrm{~km}$, DC3PT line divided into two sections is considered. The simplified model of DC3PT line is depicted in Fig. 1. Basic network description and configuration of data of transmission line used in the presented work are illustrated in Table 1. The transmission module is implemented and simulated using Simulink $\&$ Simpowersystems toolboxes of MATLAB. The recorded

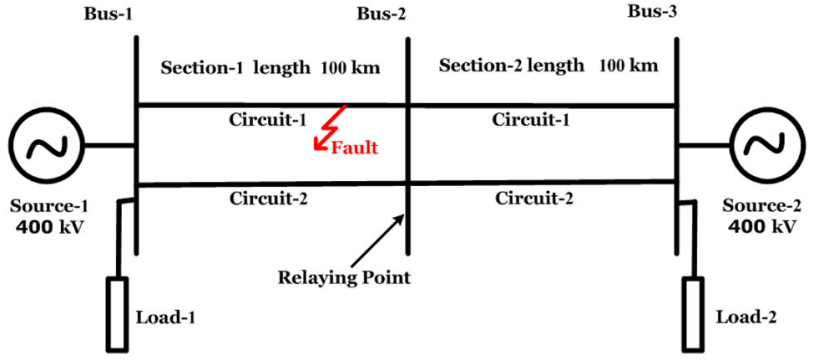

Fig. 1 Single-line diagram of DC3PT line

Table 1 Basic system description data

\begin{tabular}{llc}
\hline Parameter & Units & Nominal values \\
\hline Nominal source voltage & $(\mathrm{kV})$ & 400 \\
Earth resistivity & $(\Omega \mathrm{m})$ & 90 \\
Line length for section-1 & $(\mathrm{km})$ & 100 \\
Line length for section-2 & $(\mathrm{km})$ & 100 \\
Short-circuit capability & $(\mathrm{MVA})$ & 1250 \\
$X / R$ ratio of the source & - & 10 \\
Frequency & $(\mathrm{Hz})$ & 50 \\
Base power & $(\mathrm{MVA})$ & 200 \\
\hline
\end{tabular}

instantaneous six current inputs were sampled at $1200 \mathrm{~Hz}$ sampling frequency and then processed by normal secondorder Butterworth filter (480 Hz cut-off frequency). After that, the discrete time Fourier transform (DFT) block has been given herein to exercise the time-series currents. Next, the fundamental component of six-phase current waveforms has been estimated using DFT tool of MATLAB ${ }^{\circledR}$ software. The FES approach employs the fundamental component of six-phase currents at one terminal of line only. Phase angle of positive-sequence component, three-phase currents, and zero-sequence components of current in double-circuit line during faulty condition in section-1 are exemplified in Figs. 2, 3 , and 4, respectively. The outline of proposed FES-based directional relaying, classification, and location schemes for shunt faults is illustrated in Fig. 5.

\section{Proposed FES-based scheme}

Unlike Boolean logic which consists of the two values of 0 and 1, fuzzy logic is multivalued and the truth value of each proposition can fluctuate between 0 and 1 values. FES is a systematic procedure to modify a knowledge base system into non-linear mappings in which the formation of a procedure is finished by means of fuzzy logic. FES is easy to build and it does not require training structure to attain output. Owing to less computational work than the other computing methods, FES is preferred. Figure 6 depicts the flow of FES. Thus, the FES approach is considered for protecting from 


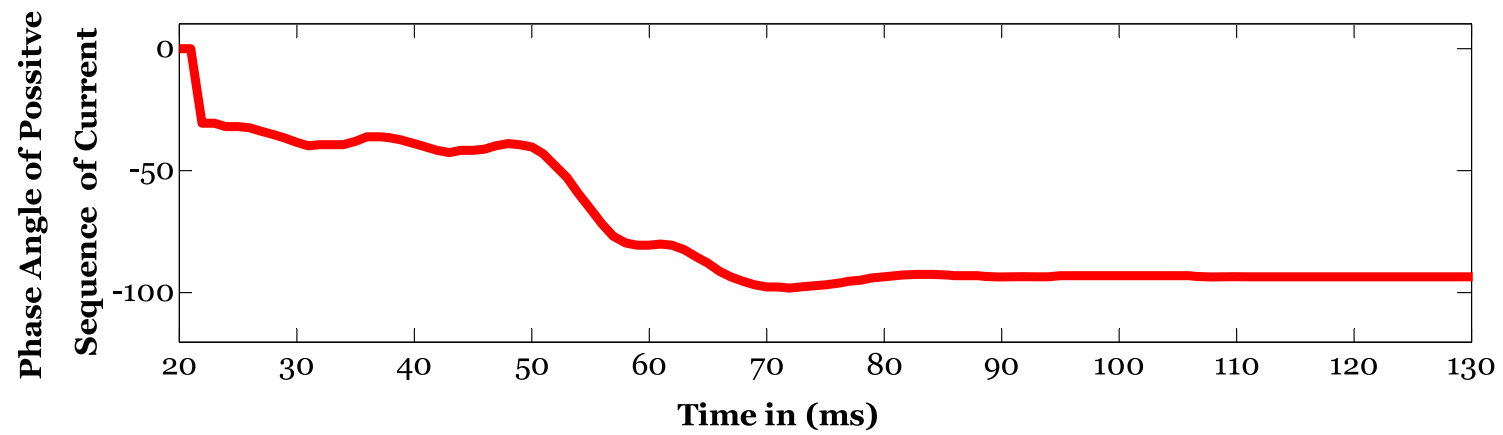

Fig. 2 Phase angle of positive-sequence component in DC3PT line during faulty condition of section-1

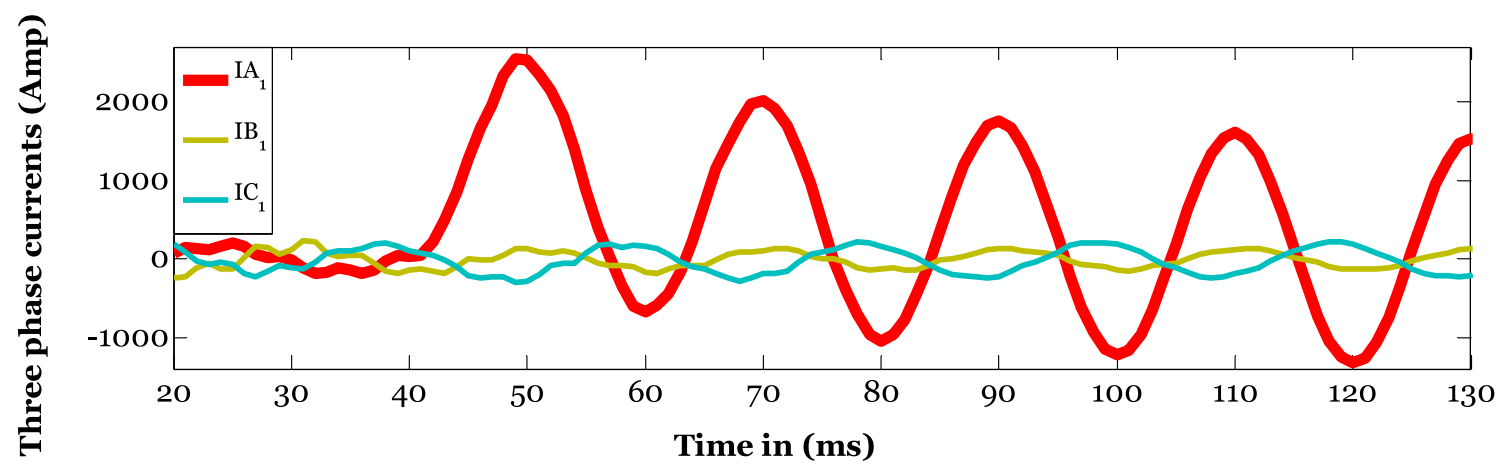

Fig. 3 Three-phase currents of DC3PT line during faulty condition

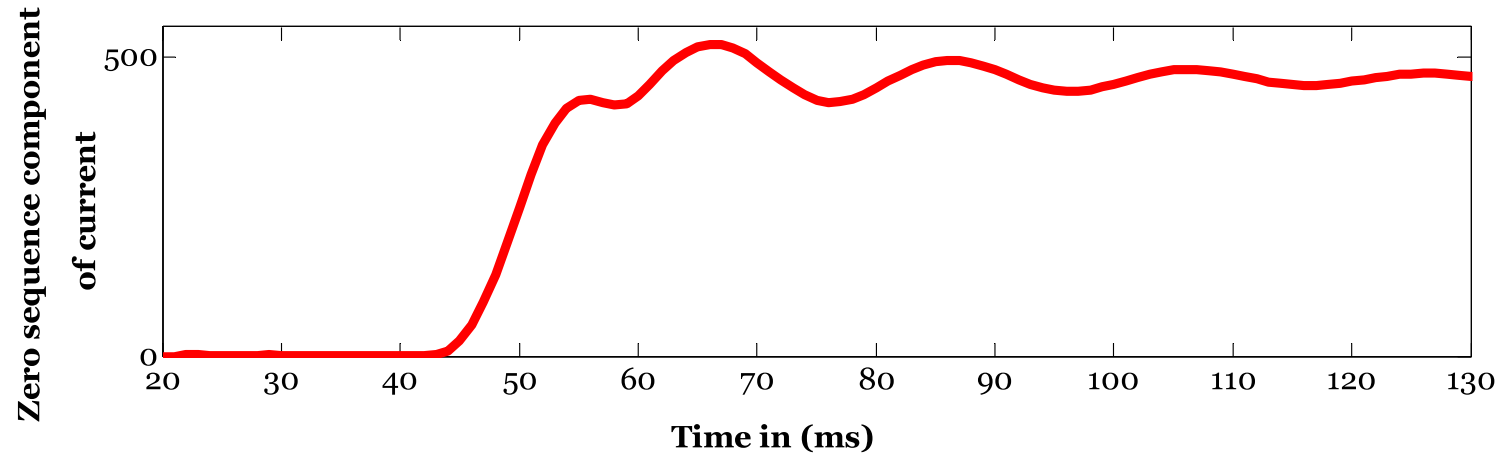

Fig. 4 Zero-sequence component of current of DC3PT line during faulty condition

various types of shunt faults. The proposed protection system consists of three different FES systems: FES-D, FES-C, and FES-L. The FES-D system is used to identify the faulted section (directional relaying), FES-C system is used to identify the faulted phases (classification), and FES-L is used to locate the fault (location). In this paper, FES networks have been developed for 22 types of faults for both sections in DC3PT lines in LabVIEW Software.

\section{FES-D modeling}

The FES-D used here is the Mamdani type. The first scheme (FES-D) has single input parameter and single output parameter. In FES-D, input taken phase angle and the output taken fault in section. The input labeled as PA and input labeled as S. The input variable is divided into three class, viz., low, medium, and high. The fuzzy output from the FES$D$ is classified into three groups, viz., S-1, S-0, and S-2. The fuzzification of input and output is using the triangular membership curves as shown in Fig. 7. The rule base is formulated for FES-D using expert knowledge on the effect of all the input variables. Three crucial decision rules that are being formulated in the process of constructing rule base for the FES-D are as follows. 


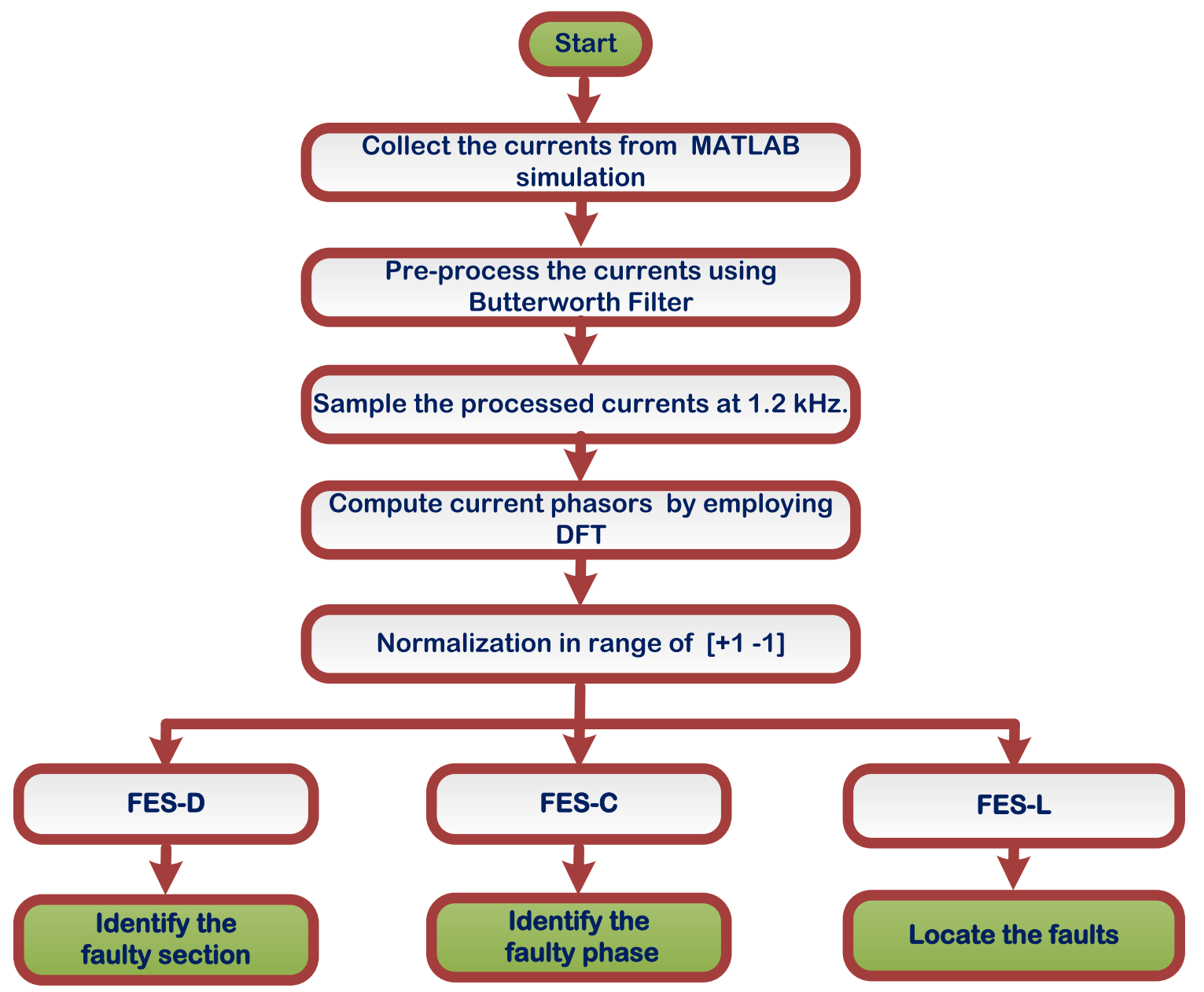

Fig. 5 The outline of proposed FES-based directional relaying, classification, and location scheme

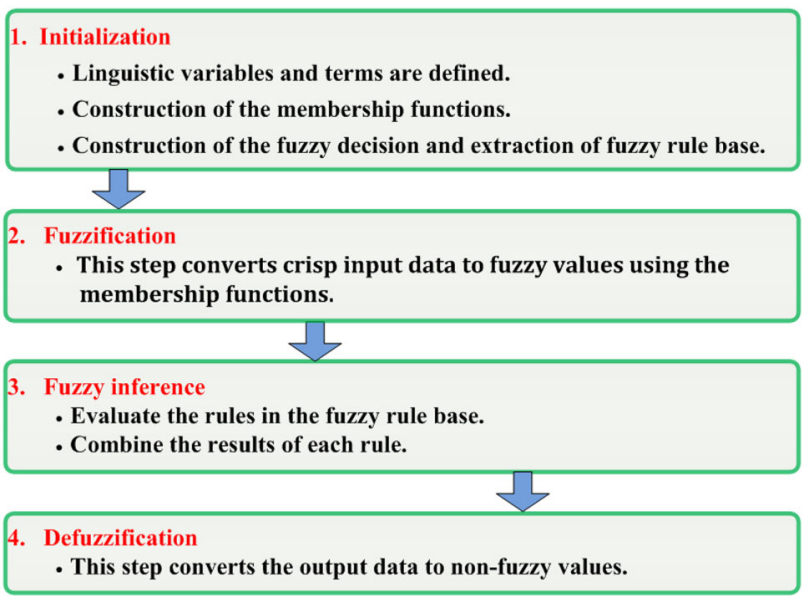

Fig. 6 The flow of FES

\section{FES-C modeling}

A number of inputs and outputs for FES-C are 7 and 7 , respectively. The fundamental component of six current and zero-sequence components of current is fed into the FES-C. The output of FES-C gives faulted phases in two circuits and ground. In this, inputs designate I1A, I1B, I1C, I2A, I2B, $\mathrm{I} 2 \mathrm{C}$, and IZ. The outputs designate $1 \mathrm{~A}, 1 \mathrm{~B}, 1 \mathrm{C}, 2 \mathrm{~A}, 2 \mathrm{~B}, 2 \mathrm{C}$, and G. Mamdani FES is picked to make decision. Based on trapezoidal memberships, each input have been divided into two divisions, viz., LOW and HIGH. Similarly, two groups of triangular memberships, viz., HEALTHY and FAULTY, are each output as depicted in Fig. 8. Total 22 IF-THEN rules are formulated for classification of shunt faults after framing input-output fuzzy sets. The 22 rules for classification of shunt faults were based on the below two conditions only.

\section{FES-L modeling}

Here, inputs to fuzzification block of FES-L are: circuit-1 with phase A current (I1A), circuit-1 with phase B current (I1B), circuit-1 with phase C current (I1C), circuit-2 with phase A current (I2A), circuit-2 with phase B current (I2B), circuit-2 with phase $\mathrm{C}$ current (I2C), and the output is the fault location $(\mathrm{L})$. The triangular memberships are labeled for 


\section{FES-D system IF-THEN rules}

1) IF (PA is Low) THEN ( $\mathrm{S}$ is $\mathrm{S}-2)$

2) IF (PA is Medium) THEN ( $\mathrm{S}$ is $\mathrm{S}-0$ )

3) IF (PA is High) THEN ( $\mathrm{S}$ is $\mathrm{S}-1)$

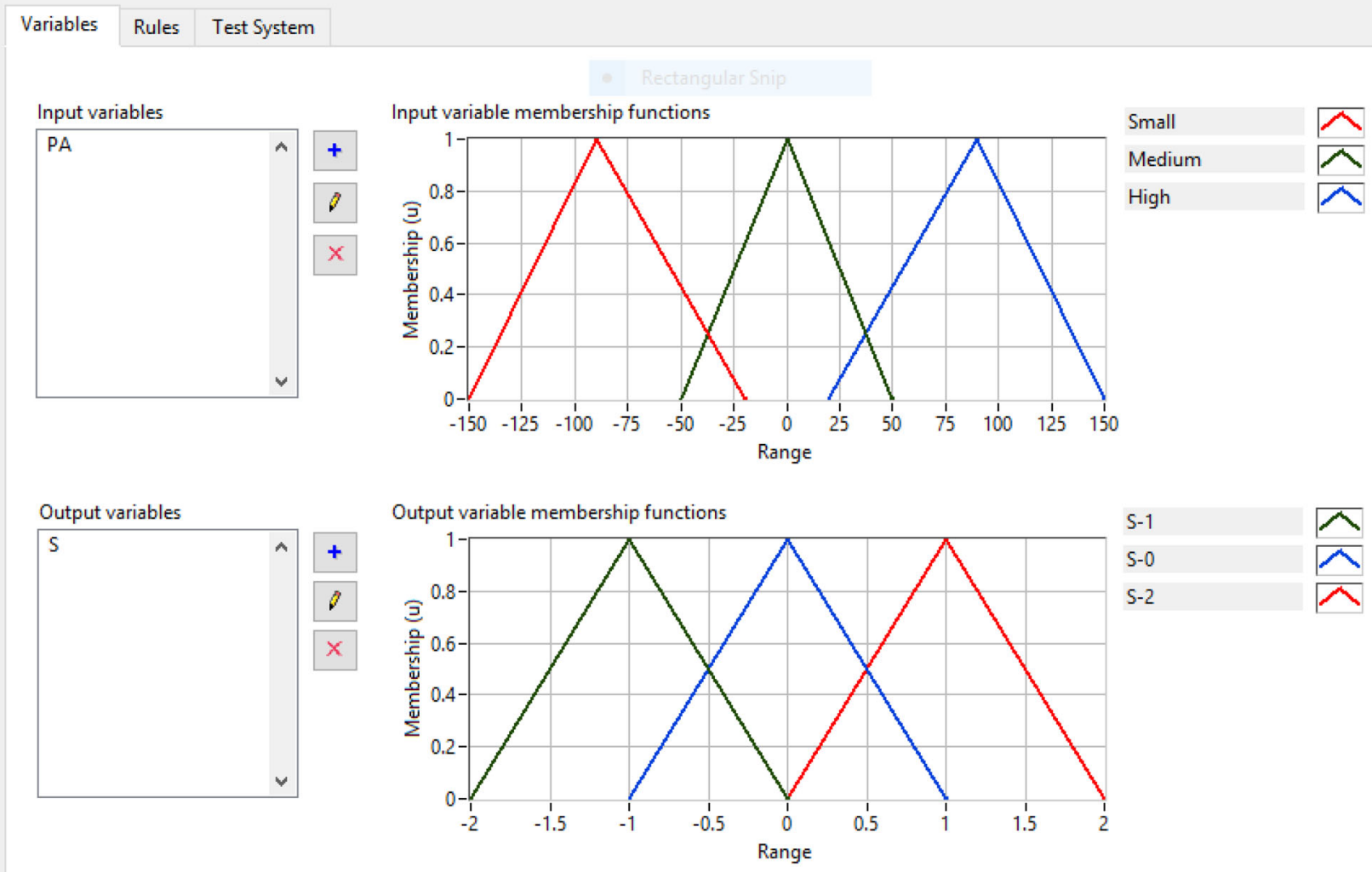

Fig. 7 Fuzzification of FIS-D input and output in LabVIEW

fuzzy mapping and six linguistics are labeled for each input such as $\mathrm{K} 1, \mathrm{~K} 2$...K6, whereas the output (L) is labeled in six linguistic values such as M1, M2 ...M6. The memberships for inputs and outputs are depicted in Fig. 9. Fuzzy rules are framed which involve IF-THEN conditional statements using Mamdani-type rules. A total of $6(6 \times 1=6)$ rules are framed using IF-THEN statements with the memberships of seven inputs and one output.

\section{Response of the proposed scheme}

The proposed scheme has been verified by data of faults on a $400-\mathrm{kV}, 50-\mathrm{Hz}$, DC3PT system in the LabVIEW. Testing is vital to verify the performance of fuzzy-based fault directional relaying, classifier, and locator. The proposed fuzzy-based fault directional relaying, classifier, and locator is verified using test data considering all types of shunt faults with change in fault location (L) between 1 and $199 \mathrm{~km}$, resistances between 1 and $140 \Omega$, and inception angle between $0^{\circ}$ and $360^{\circ}$. Total 13,000 faults are simulated and tested. Some of the test results corresponding to directional relaying, classification, and location estimation are explained in the subsequent subsections.

\section{Response of FES-D}

When there is no fault, the output of FES-D will be zero value. If faults occur, the output starts adjusting to either -1 or +1 depending on the section- 1 or section- 2 faults of line, respectively. The output of direction relaying scheme for various faults with changing fault location (L), resistances 


\section{FES-C system IF-THEN rule conditions}

1) IF current in phase is LOW THEN phase is HEALTHY.

2) IF current in phase is HIGH THEN phase is FAULTY.

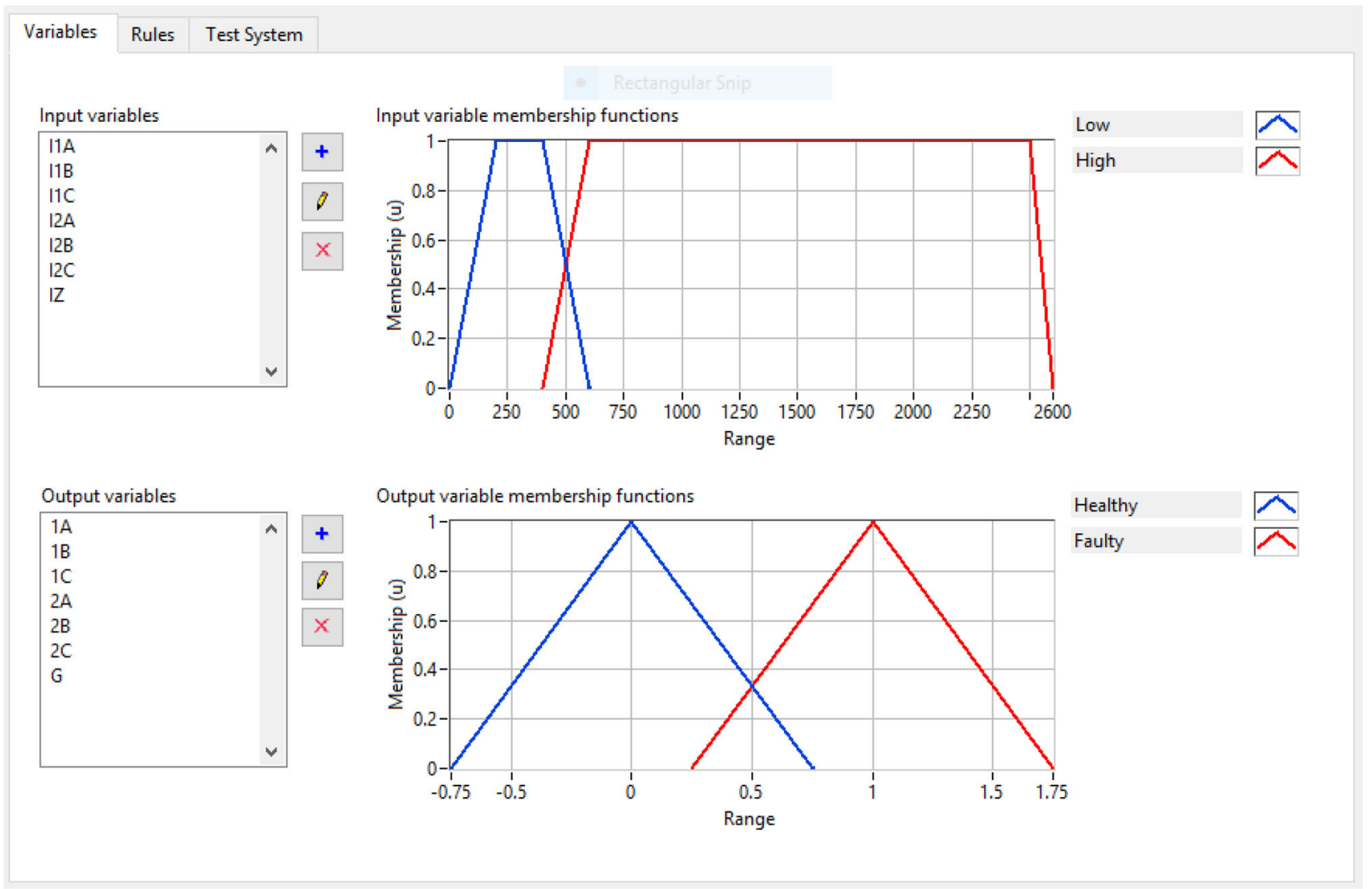

Fig. 8 Fuzzification of FIS-C input and output in LabVIEW

(R), and fault inception angle (FIA) in section-1 or section-2 direction from bus-2 is summarized in Table 2. One sample of result for FES-D in LabVIEW fuzzy software is given in Fig. 10. It is proved that most of the samples can be identified by fault sections correctly. The FES-D reach setting is below $99.892 \%$ of total line.

\section{Response of FES-C}

The response of FES-C will be in terms of no-fault (0) and fault (1) in the phases. The results obtained by FES-C for classifying faults based on LabVIEW in case of different FIA, different locations, and different resistances are summarized in Table 2. The accuracy in faulty classification is obtained using Eq. (1). One sample of result for FES-C in LabVIEW fuzzy software is given in Fig. 11. After checking the proposed fuzzy-based shunt fault classifier, it has been determined that it can correctly classify all possible types of shunt faults, i.e., accuracy of $99.983 \%$.

\section{Response of FES-L}

Simulation and experimental results are obtained to further verify the performance of the proposed scheme for location. Table 2 presents also the performance results of FES-L for the different inception angles, different resistances, and the different types. In the table, \% error is computed from Eq. (2). One sample of result for FES-L in Labview fuzzy software is illustrated in Fig. 12. The proposed approach measures precisely the fault location with the \% error within $0.32 \%$ for most of the test cases. Performance analysis of FES-L shows that the fault information is more reliable locates the faulty line: 


\section{FES-L system IF-THEN rule}

1) IF (I1 A is $\mathrm{K} 1$ ) or (I1B is $\mathrm{K} 1$ ) or (I1C is $\mathrm{K} 1$ ) or (I2A is $\mathrm{K} 1$ ) or (I2B is $\mathrm{K} 1$ ) or (I2C is K1) THEN (L is M6)

2) IF (I1A is K2) or (I1B is K2) or (I1C is K2) or (I2A is K2) or (I2B is K2) or (I2C is K2) THEN (L is M5)

3) IF (I1A is K3) or (I1B is K3) or (I1C is K3) or (I2A is K3) or (I2B is K3) or (I2C is K3) THEN (L is M4)

4) IF (I1A is K4) or (I1B is K4) or (I1C is K4) or (I2A is K4) or (I2B is K4) or (I2C is K4) THEN (L is M3)

5) IF (I1A is K5) or (I1B is K5) or (I1C is K5) or (I2A is K5) or (I2B is K5) or (I2C is K5) THEN (L is M2)

6) IF (I1A is K6) or (I1B is K6) or (I1C is K6) or (I2A is K6) or (I2B is K6) or (I2C is K6) THEN (L is M1)
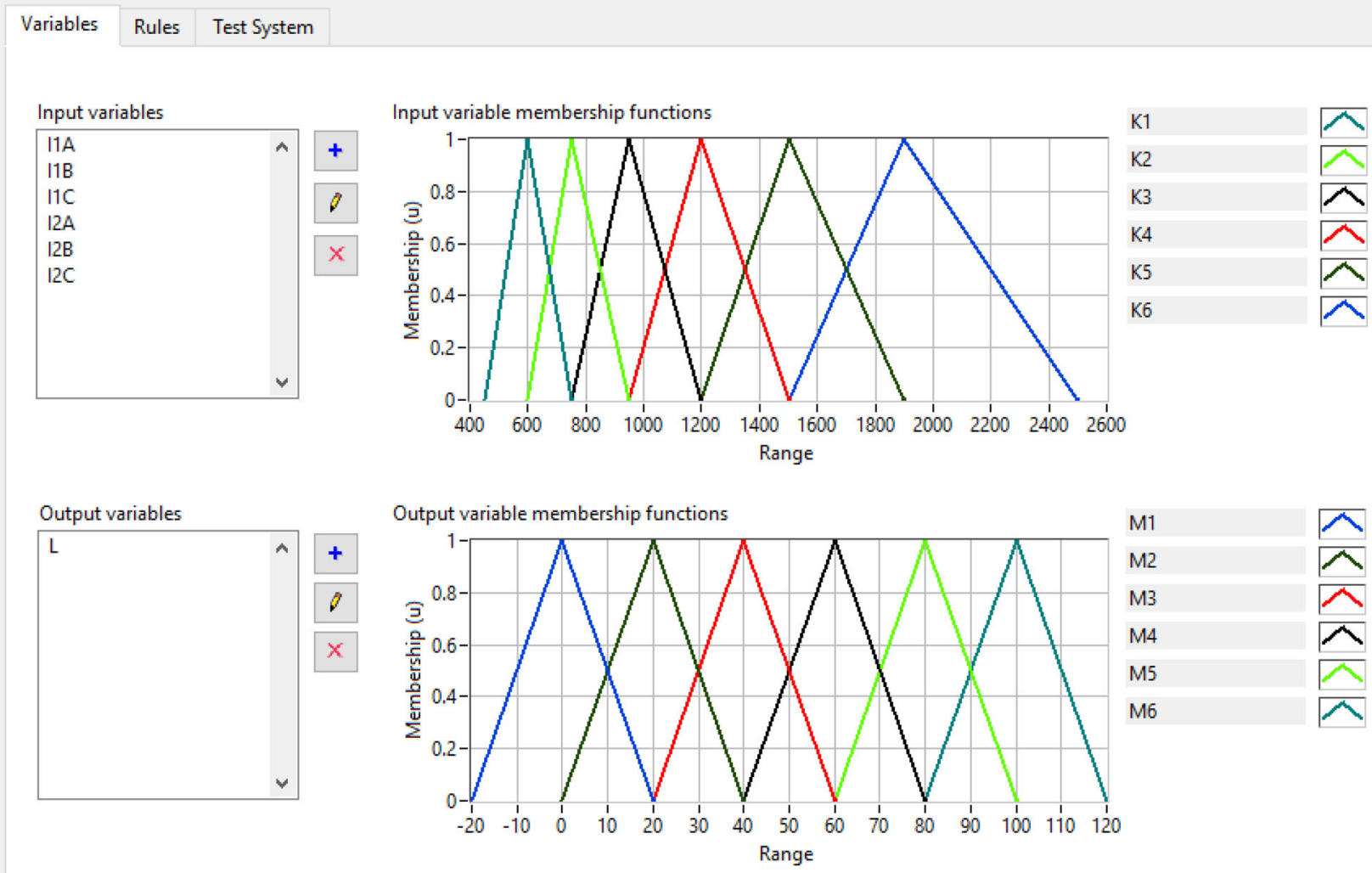

Fig. 9 Fuzzification of FIS-L input and output in LabVIEW

\section{Comparative assessment}

Accuracy $=\frac{T}{N} \times 100$,

where $T$ is the number of testing samples classified correctly; $N$ is the total number of testing samples.

$\%$ Error $=\left|\frac{L 1-L 2}{L} \times 100\right|$,

where $L 1$ is the true fault location; $L 2$ is the measured fault location; $L$ line length.
Quantitative comparison of the proposed technique with some other soft-computing-based techniques is given in Table 3. It can be observed that $\%$ error of the suggested method is lower than error of \% earlier methods in $[6,9,15$, $17,25,35,38]$, which is a feature over earlier methods. The reach setting in [4] and accuracy in [8] is $99.5 \%$ and $98.36 \%$, respectively. The reach setting and accuracy of the FES is $99.892 \%$ and $99.983 \%$ respectively. Furthermore, the two terminal data used in [23, 24], whereas the suggested FES used source end data. Furthermore, past papers have published an ANN $[4,6,17,25]$ and the suggested method designed 
Table 2 Performance of FES-D, FES-C, and FES-L

\begin{tabular}{|c|c|c|c|c|c|c|c|c|c|c|c|c|c|c|c|}
\hline \multirow[t]{2}{*}{ Fault section } & \multirow{2}{*}{$\begin{array}{l}\text { Parameter } \\
\text { varied }\end{array}$} & \multirow[t]{2}{*}{ Type } & \multirow[t]{2}{*}{$L(\mathrm{~km})$} & \multirow[t]{2}{*}{ FIA $\left(^{\circ}\right)$} & \multirow[t]{2}{*}{$R(\Omega)$} & \multirow[t]{2}{*}{ FES-D } & \multicolumn{7}{|c|}{ FES-C } & \multirow[t]{2}{*}{ FES-L } & \multirow[t]{2}{*}{$\%$ Error } \\
\hline & & & & & & & $1 \mathrm{~A}$ & $1 \mathrm{~B}$ & $1 \mathrm{C}$ & $2 \mathrm{~A}$ & $2 \mathrm{~B}$ & $2 \mathrm{C}$ & G & & \\
\hline \multirow[t]{24}{*}{ Section-1 } & \multirow{6}{*}{$\begin{array}{l}\text { Fault type is } \\
\text { changing } \\
\text { and } L, \\
\text { FIA, } R \text { are } \\
\text { fixed }\end{array}$} & $1 \mathrm{~A}-\mathrm{G}$ & 21 & 45 & 10 & -1 & 1 & 0 & 0 & 0 & 0 & 0 & 1 & 21.36 & 0.18 \\
\hline & & $1 \mathrm{AB}$ & 21 & 45 & 10 & -1 & 1 & 1 & 0 & 0 & 0 & 0 & 0 & 20.76 & 0.12 \\
\hline & & $2 \mathrm{C}-\mathrm{G}$ & 21 & 45 & 10 & -1 & 0 & 0 & 0 & 0 & 0 & 1 & 1 & 21.18 & 0.09 \\
\hline & & $2 \mathrm{ABC}$ & 21 & 45 & 10 & -1 & 0 & 0 & 0 & 1 & 1 & 1 & 0 & 21.42 & 0.21 \\
\hline & & $2 \mathrm{BC}$ & 21 & 45 & 10 & -1 & 0 & 0 & 0 & 0 & 1 & 1 & 0 & 21.25 & 0.13 \\
\hline & & $1 \mathrm{ABC}$ & 21 & 45 & 10 & -1 & 1 & 1 & 1 & 0 & 0 & 0 & 1 & 21.38 & 0.19 \\
\hline & \multirow{6}{*}{$\begin{array}{l}L \text { is } \\
\text { changing } \\
\text { and fault } \\
\text { type, FIA, } \\
R \text { are fixed }\end{array}$} & $1 \mathrm{~B}-\mathrm{G}$ & 12 & 90 & 30 & -1 & 0 & 1 & 0 & 0 & 0 & 0 & 1 & 12.04 & 0.02 \\
\hline & & $1 \mathrm{~B}-\mathrm{G}$ & 26 & 90 & 30 & -1 & 0 & 1 & 0 & 0 & 0 & 0 & 1 & 25.74 & 0.13 \\
\hline & & $1 \mathrm{~B}-\mathrm{G}$ & 34 & 90 & 30 & -1 & 0 & 1 & 0 & 0 & 0 & 0 & 1 & 33.84 & 0.08 \\
\hline & & $1 \mathrm{~B}-\mathrm{G}$ & 56 & 90 & 30 & -1 & 0 & 1 & 0 & 0 & 0 & 0 & 1 & 56.30 & 0.15 \\
\hline & & $1 \mathrm{~B}-\mathrm{G}$ & 61 & 90 & 30 & -1 & 0 & 1 & 0 & 0 & 0 & 0 & 1 & 60.92 & 0.04 \\
\hline & & $1 \mathrm{~B}-\mathrm{G}$ & 85 & 90 & 30 & -1 & 0 & 1 & 0 & 0 & 0 & 0 & 1 & 85.48 & 0.24 \\
\hline & \multirow{6}{*}{$\begin{array}{l}\text { FIA is } \\
\text { changing } \\
\text { and fault } \\
\text { type, } L, R \\
\text { are fixed }\end{array}$} & $1 \mathrm{ABC}-\mathrm{G}$ & 74 & 5 & 40 & -1 & 1 & 1 & 1 & 0 & 0 & 0 & 1 & 74.22 & 0.11 \\
\hline & & $1 \mathrm{ABC}-\mathrm{G}$ & 74 & 50 & 40 & -1 & 1 & 1 & 1 & 0 & 0 & 0 & 1 & 74.64 & 0.32 \\
\hline & & $1 \mathrm{ABC}-\mathrm{G}$ & 74 & 120 & 40 & -1 & 1 & 1 & 1 & 0 & 0 & 0 & 1 & 74.08 & 0.04 \\
\hline & & $1 \mathrm{ABC}-\mathrm{G}$ & 74 & 330 & 40 & -1 & 1 & 1 & 1 & 0 & 0 & 0 & 1 & 74.44 & 0.22 \\
\hline & & $1 \mathrm{ABC}-\mathrm{G}$ & 74 & 360 & 40 & -1 & 1 & 1 & 1 & 0 & 0 & 0 & 1 & 73.86 & 0.07 \\
\hline & & $1 \mathrm{ABC}-\mathrm{G}$ & 74 & 240 & 40 & -1 & 1 & 1 & 1 & 0 & 0 & 0 & 1 & 74.56 & 0.28 \\
\hline & \multirow{6}{*}{$\begin{array}{l}R \text { is } \\
\text { changing } \\
\text { and } L, \\
\text { fault type, } \\
\text { FIA, are } \\
\text { fixed }\end{array}$} & $2 \mathrm{AC}$ & 92 & 135 & 15 & -1 & 0 & 0 & 0 & 1 & 0 & 1 & 0 & 92.26 & 0.13 \\
\hline & & $2 \mathrm{AC}$ & 92 & 135 & 30 & -1 & 0 & 0 & 0 & 1 & 0 & 1 & 0 & 92.52 & 0.26 \\
\hline & & $2 \mathrm{AC}$ & 92 & 135 & 45 & -1 & 0 & 0 & 0 & 1 & 0 & 1 & 0 & 91.70 & 0.15 \\
\hline & & $2 \mathrm{AC}$ & 92 & 135 & 60 & -1 & 0 & 0 & 0 & 1 & 0 & 1 & 0 & 92.12 & 0.06 \\
\hline & & $2 \mathrm{AC}$ & 92 & 135 & 80 & -1 & 0 & 0 & 0 & 1 & 0 & 1 & 0 & 91.82 & 0.09 \\
\hline & & $2 \mathrm{AC}$ & 92 & 135 & 100 & -1 & 0 & 0 & 0 & 1 & 0 & 1 & 0 & 92.16 & 0.08 \\
\hline \multirow[t]{18}{*}{ Section-2 } & \multirow{6}{*}{$\begin{array}{l}\text { Fault type is } \\
\text { changing } \\
L, \text { FIA, } R \\
\text { are fixed }\end{array}$} & $1 \mathrm{C}-\mathrm{G}$ & 25 & 180 & 60 & 1 & 0 & 0 & 1 & 0 & 0 & 0 & 1 & 25.22 & 0.11 \\
\hline & & $1 \mathrm{ABC}$ & 25 & 180 & 60 & 1 & 1 & 1 & 1 & 0 & 0 & 0 & 0 & 25.34 & 0.17 \\
\hline & & $2 \mathrm{~A}-\mathrm{G}$ & 25 & 180 & 60 & 1 & 0 & 0 & 0 & 1 & 0 & 0 & 1 & 24.88 & 0.06 \\
\hline & & $2 \mathrm{AC}$ & 25 & 180 & 60 & 1 & 0 & 0 & 0 & 1 & 0 & 1 & 0 & 24.98 & 0.01 \\
\hline & & $2 \mathrm{AC}-\mathrm{G}$ & 25 & 180 & 60 & 1 & 0 & 0 & 0 & 1 & 0 & 1 & 1 & 25.20 & 0.10 \\
\hline & & $1 \mathrm{AB}$ & 25 & 180 & 60 & 1 & 1 & 1 & 0 & 0 & 0 & 0 & 0 & 25.16 & 0.08 \\
\hline & \multirow{6}{*}{$\begin{array}{l}L \text { is } \\
\text { changing } \\
\text { and fault } \\
\text { type, FIA, } \\
R \text { are fixed }\end{array}$} & $2 \mathrm{ABC}$ & 11 & 275 & 90 & 1 & 0 & 0 & 0 & 1 & 1 & 1 & 0 & 11.28 & 0.14 \\
\hline & & $2 \mathrm{ABC}$ & 19 & 275 & 90 & 1 & 0 & 0 & 0 & 1 & 1 & 1 & 0 & 19.34 & 0.17 \\
\hline & & $2 \mathrm{ABC}$ & 68 & 275 & 90 & 1 & 0 & 0 & 0 & 1 & 1 & 1 & 0 & 68.45 & 0.22 \\
\hline & & $2 \mathrm{ABC}$ & 95 & 275 & 90 & 1 & 0 & 0 & 0 & 1 & 1 & 1 & 0 & 95.60 & 0.30 \\
\hline & & $2 \mathrm{ABC}$ & 38 & 275 & 90 & 1 & 0 & 0 & 0 & 1 & 1 & 1 & 0 & 38.42 & 0.21 \\
\hline & & $2 \mathrm{ABC}$ & 56 & 275 & 90 & 1 & 0 & 0 & 0 & 1 & 1 & 1 & 0 & 56.30 & 0.15 \\
\hline & \multirow{6}{*}{$\begin{array}{l}\text { FIA is } \\
\text { changing } \\
\text { and fault } \\
\text { type, } L, R \\
\text { are fixed }\end{array}$} & $1 \mathrm{C}-\mathrm{G}$ & 39 & 30 & 120 & 1 & 0 & 0 & 1 & 0 & 0 & 0 & 1 & 39.27 & 0.13 \\
\hline & & $1 \mathrm{C}-\mathrm{G}$ & 39 & 160 & 120 & 1 & 0 & 0 & 1 & 0 & 0 & 0 & 1 & 39.23 & 0.11 \\
\hline & & $1 \mathrm{C}-\mathrm{G}$ & 39 & 200 & 120 & 1 & 0 & 0 & 1 & 0 & 0 & 0 & 1 & 38.44 & 0.22 \\
\hline & & $1 \mathrm{C}-\mathrm{G}$ & 39 & 350 & 120 & 1 & 0 & 0 & 1 & 0 & 0 & 0 & 1 & 39.10 & 0.05 \\
\hline & & $1 \mathrm{C}-\mathrm{G}$ & 39 & 80 & 120 & 1 & 0 & 0 & 1 & 0 & 0 & 0 & 1 & 39.25 & 0.12 \\
\hline & & $1 \mathrm{C}-\mathrm{G}$ & 39 & 290 & 120 & 1 & 0 & 0 & 1 & 0 & 0 & 0 & 1 & 39.15 & 0.07 \\
\hline
\end{tabular}


Table 2 continued

\begin{tabular}{|c|c|c|c|c|c|c|c|c|c|c|c|c|c|c|c|}
\hline \multirow[t]{2}{*}{ Fault section } & \multirow{2}{*}{$\begin{array}{l}\text { Parameter } \\
\text { varied }\end{array}$} & \multirow[t]{2}{*}{ Type } & \multirow[t]{2}{*}{$L(\mathrm{~km})$} & \multirow[t]{2}{*}{ FIA $\left(^{\circ}\right)$} & \multirow[t]{2}{*}{$R(\Omega)$} & \multirow[t]{2}{*}{ FES-D } & \multicolumn{7}{|c|}{ FES-C } & \multirow[t]{2}{*}{ FES-L } & \multirow[t]{2}{*}{$\%$ Error } \\
\hline & & & & & & & $1 \mathrm{~A}$ & $1 \mathrm{~B}$ & $1 \mathrm{C}$ & $2 \mathrm{~A}$ & $2 \mathrm{~B}$ & $2 \mathrm{C}$ & $\mathrm{G}$ & & \\
\hline & \multirow{6}{*}{$\begin{array}{l}R \text { is } \\
\text { changing } \\
\text { and L, } \\
\text { Fault type, } \\
\text { FIA, are } \\
\text { fixed }\end{array}$} & $2 \mathrm{AB}-\mathrm{G}$ & 68 & 315 & 47 & 1 & 0 & 0 & 0 & 1 & 1 & 0 & 1 & 68.04 & 0.02 \\
\hline & & $2 \mathrm{AB}-\mathrm{G}$ & 68 & 315 & 85 & 1 & 0 & 0 & 0 & 1 & 1 & 0 & 1 & 67.78 & 0.11 \\
\hline & & $2 \mathrm{AB}-\mathrm{G}$ & 68 & 315 & 96 & 1 & 0 & 0 & 0 & 1 & 1 & 0 & 1 & 68.09 & 0.04 \\
\hline & & $2 \mathrm{AB}-\mathrm{G}$ & 68 & 315 & 124 & 1 & 0 & 0 & 0 & 1 & 1 & 0 & 1 & 67.86 & 0.07 \\
\hline & & $2 \mathrm{AB}-\mathrm{G}$ & 68 & 315 & 9 & 1 & 0 & 0 & 0 & 1 & 1 & 0 & 1 & 67.80 & 0.10 \\
\hline & & $2 \mathrm{AB}-\mathrm{G}$ & 68 & 315 & 36 & 1 & 0 & 0 & 0 & 1 & 1 & 0 & 1 & 68.12 & 0.06 \\
\hline
\end{tabular}

without require large data, training, and complexity. Development of FES is easy as compared to other frameworks. As described above, it has noticeable that the suggested method provides satisfactory results for direction relaying, classification, and location. Thus, the FES is fit for direction relaying, classification, and location in double-circuit line than all other frameworks.

\section{Conclusions remarks}

Fault protection in transmission lines is a very important issue nowadays. This paper presented a system for direction relaying, classification, and location of faults in doublecircuit line based on fuzzy expert system. In this paper, an effort has made to enhance reach setting to directional relaying, accuracy to fault classification and percentage error to fault location. The reported study performed in the MATLAB and LabVIEW platform using fuzzy toolbox. The key benefits of the proposed approach are that it relies only on

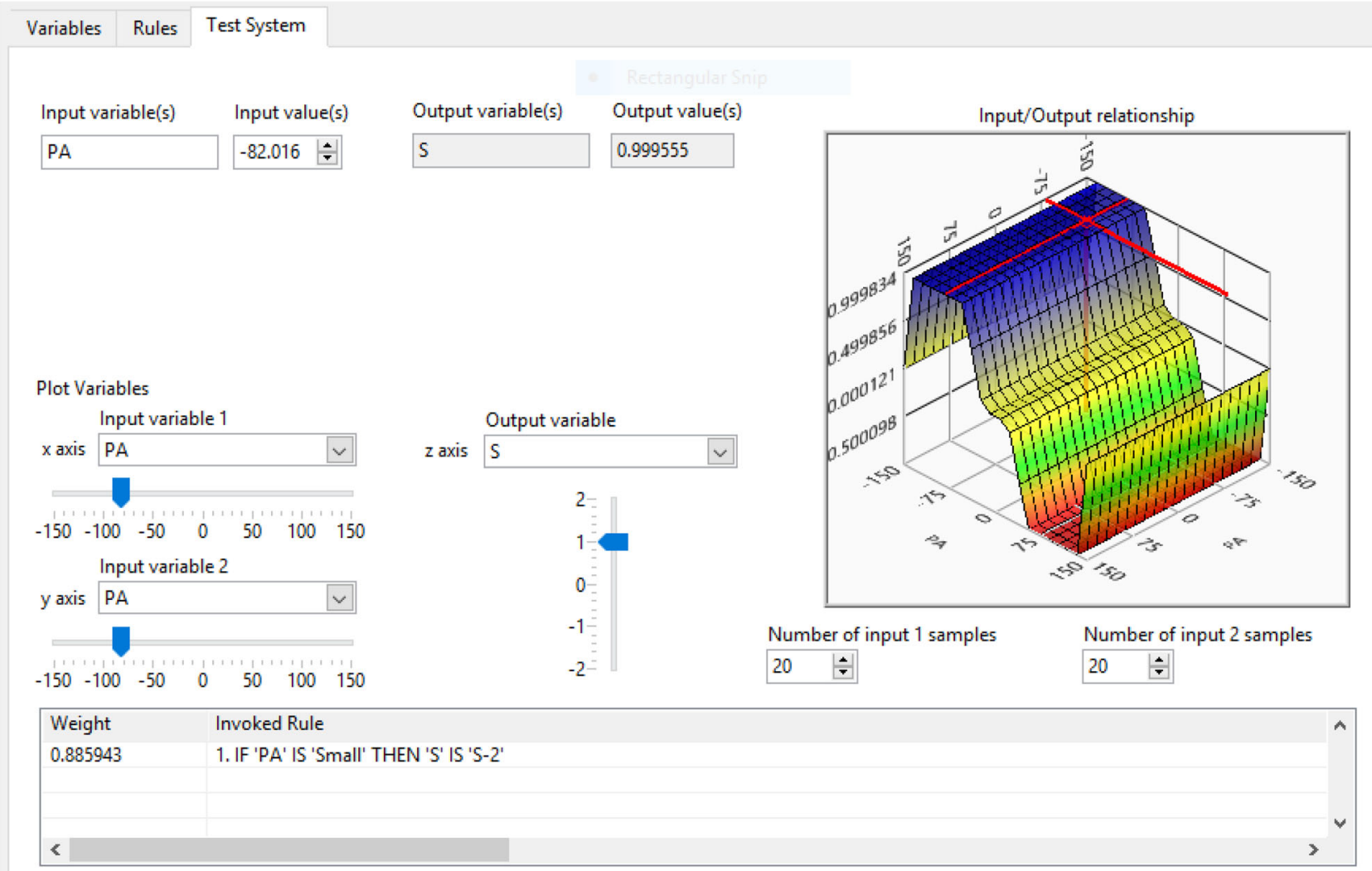

Fig. 10 FES-D output in LabVIEW 


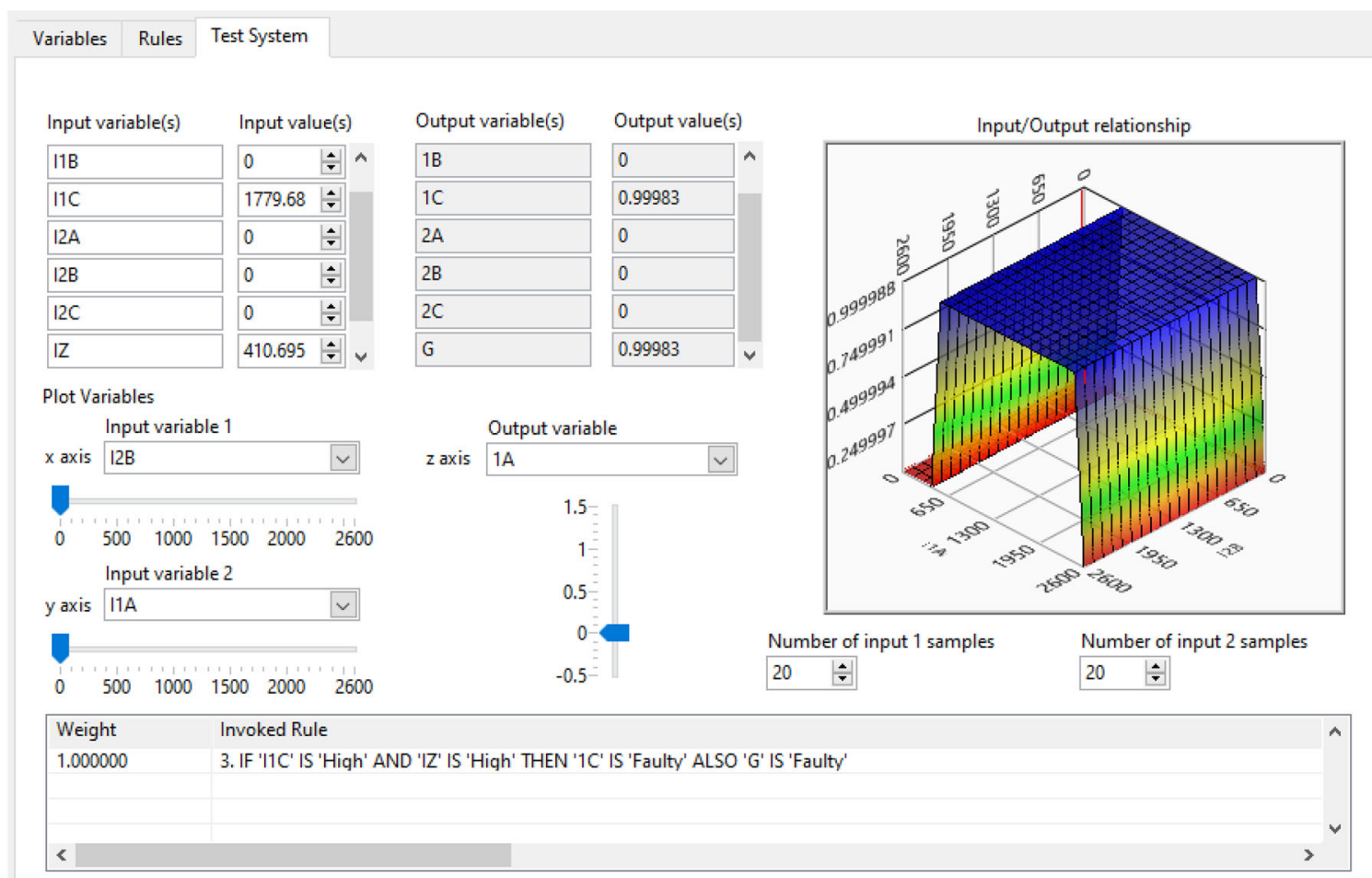

Fig. 11 FES-C output in LabVIEW

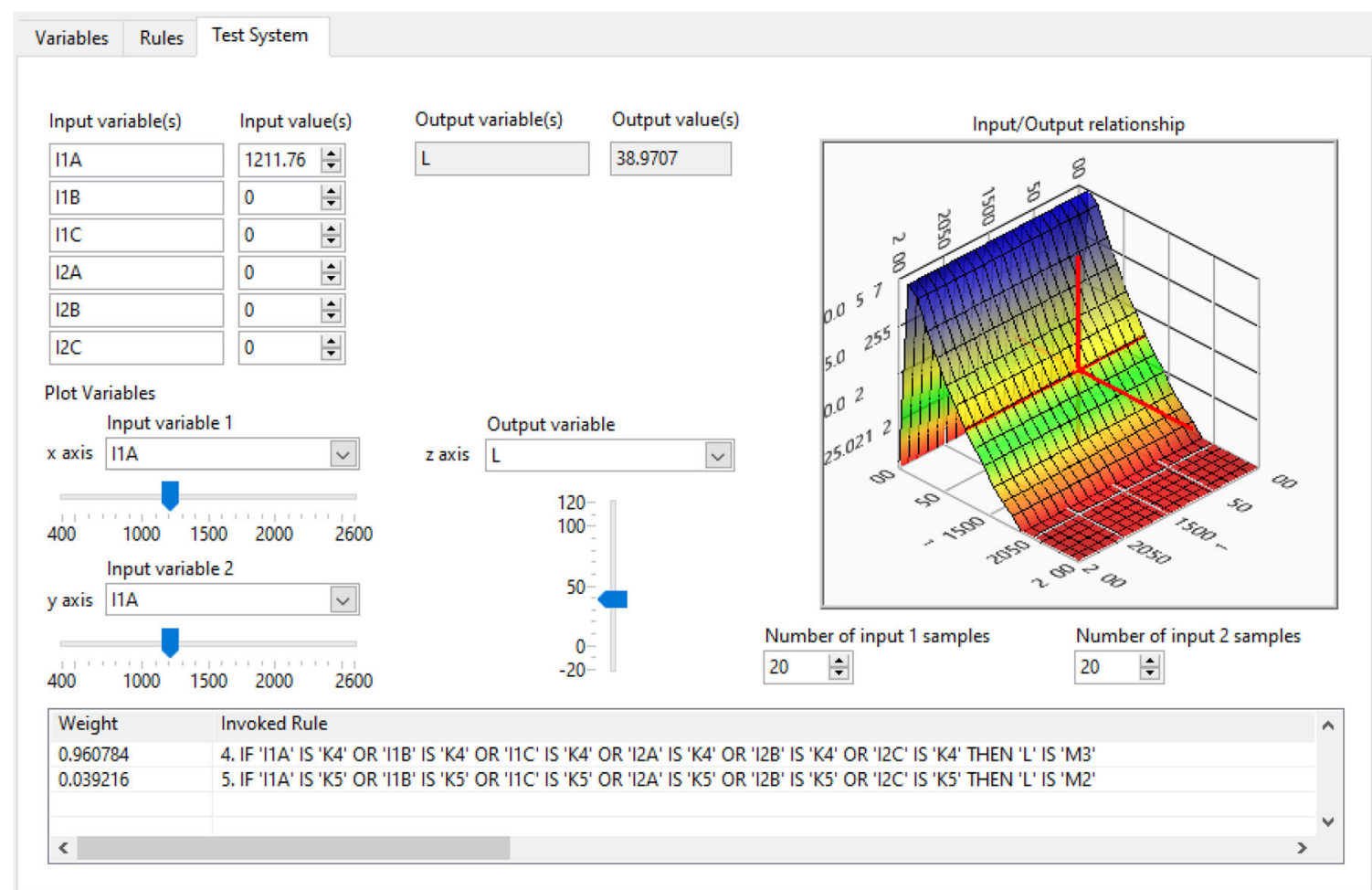

Fig. 12 FIS-L output in LabVIEW 
Table 3 Comparison with some other methods

\begin{tabular}{|c|c|c|c|c|c|}
\hline References & Protection function & Method used & Error $(\%)$ & Reach setting $(\%)$ & Accuracy $(\%)$ \\
\hline [4] & Direction relaying & ANN & - & 99.5 & - \\
\hline [6] & $\begin{array}{l}\text { Direction relaying, classification, } \\
\text { and location }\end{array}$ & Modular ANN & 0.675 & 99 & - \\
\hline [8] & Location and classification & Support vector machine & 0.21 & - & 98.36 \\
\hline [9] & Classification and location & ANN & 0.73 & - & - \\
\hline [17] & Classification and location & ANN & 0.41 & - & 99.9 \\
\hline$[15]$ & Section identification and location & Taylor series expansion & 3.63 & - & - \\
\hline [35] & Classification and location & FES & 0.4 & - & 99.93 \\
\hline [38] & $\begin{array}{l}\text { Direction relaying, classification, } \\
\text { and location }\end{array}$ & FES & 0.504 & 99.7 & 99.96 \\
\hline [25] & $\begin{array}{l}\text { Direction relaying, classification, } \\
\text { and location }\end{array}$ & ANN & 0.60 & 99 & - \\
\hline Proposed scheme & $\begin{array}{l}\text { Direction relaying, classification, } \\
\text { and location }\end{array}$ & FES & 0.32 & 99.892 & 99.983 \\
\hline
\end{tabular}

currents and based only on communication at the source bus. Various types of faults, under changing fault cases such as location of fault from bus- 2 terminal (1-99 km) in both sides, $R(1-140 \Omega)$ and FIA $\left(0^{\circ}-360^{\circ}\right)$, have been investigated. The performance of presented method has been validated by simulating number of fault tests. Furthermore, the three systems yield acceptable performance against $L$, FIA fault type and $R$. The fault section and type are correctly identified, and the error $(\%)$ does not exceed $0.32 \%$ for all simulated fault cases. The fault location results' comparison of FES and other techniques confirms that FES is more feasible in DC3PT.

\section{Future scope}

- Detailed analytical investigation can be carried out for DC3PT.

- Further same experimental study can be conducted to investigate the intercircuit faults and evolving faults.

Open Access This article is licensed under a Creative Commons Attribution 4.0 International License, which permits use, sharing, adaptation, distribution and reproduction in any medium or format, as long as you give appropriate credit to the original author(s) and the source, provide a link to the Creative Commons licence, and indicate if changes were made. The images or other third party material in this article are included in the article's Creative Commons licence, unless indicated otherwise in a credit line to the material. If material is not included in the article's Creative Commons licence and your intended use is not permitted by statutory regulation or exceeds the permitted use, you will need to obtain permission directly from the copyright holder. To view a copy of this licence, visit http://creativecomm ons.org/licenses/by/4.0/.

\section{References}

1. Yalcin MA, Turan M and Demir Z (1999) Effects of transmission line faults on dynamic voltage stability, powertech budapest 99 . Abstract Records (Cat. No. 99EX376), Budapest, Hungary

2. Wang A, Chen Q, Zhou Z (2008) Effects of un-transposed UHV transmission line on fault analysis of power systems. Trans Tianjin Univ 14:231-234

3. Peter E (2014) Effect of high fault currents on transmission lines. Wiley Online Linrary, Amsterdam (Chapter 14)

4. Yadav A, Dash Y, Ashok V (2016) ANN based directional relaying scheme for protection of Korba-Bhilai transmission line of Chhattisgarh State. Prot Control Modern Power Syst 1:1-13

5. Gao H, Crossley PA (2005) Directional relay for EHV transmission lines using positive sequence fault components. In: Proceedings of IEEE Russia Power Tech. St. Petersburg

6. Koley E, Verma K, Ghosh S (2016) A modular neuro-wavelet based non-unit protection scheme for zone identification and fault location in six phase transmission line. Neural Comput Appl 28(6):1369-1385

7. Koley E, Verma K, Ghosh S (2015) An improved fault detection classification and location scheme based on wavelet transform and artificial neural network for six phase transmission line using single end data only. Springer Plus 551(4):1-22

8. Ray P, Mishra DP (2016) Support vector machine based fault classification and location of a long transmission line. Eng Sci Technol Int J 19(3):1368-1380

9. Koley E, Yadav A, Thoke AS (2015) A new single-ended artificial neural network-based protection scheme for shunt faults in six-phase transmission line. Int Trans Electr Energy Syst 25(7):1257-1280

10. Adly R, Sehiemy A, Elsadd M, Abdelaziz AY (2019) A novel wavelet packet transform based fault identification procedures in HV transmission line based on current signals. Appl Power Eng $8(1): 11-21$

11. Adly R, Sehiemy A, Elsadd M, Abdelaziz AY (2017) A directional protection scheme during single pole tripping. Electric Power Syst Res 144:197-207

12. Zhang Ke, Zhu Y, Liu X (2019) A fault locating method for multi-branch hybrid transmission lines in wind farm based on redundancy parameter estimation. J Mod Power Syst Clean Energy 7(5):1033-1043 
13. Mishra SK, Tripathy LN (2019) A critical fault detection analysis $\&$ fault time in a UPFC transmission line. Prot Control Mod Power Syst 4:3. https://doi.org/10.1186/s41601-019-0117-5

14. Makwana VH, Bhalja BR (2012) A new digital distance relaying scheme for series-compensated double-circuit line during open conductor and ground fault. IEEE Trans Power Deliv 27(2):910-917

15. Saber A (2019) A new fault location technique for four circuit series compensated transmission lines. Electr Energy Syst 29(4):1-15

16. Swetapadma A, Yadav A (2015) High-speed directional relaying using adaptive neuro-fuzzy inference system and fundamental component of currents. IEEJ Trans Electr Electronic Eng 10:653-663

17. Kumar N, Chakravarthy M (2018) Simultaneous fault classification and localization scheme in six phase transmission line using artificial neural networks. J Adv Res Dyn Control Syst 10(3):342-349

18. Yadav A, Dash Y (2014) An overview of transmission line protection by artificial neural network: fault detection, fault classification, fault location, and fault direction discrimination. Adv Artif Neural Syst. https://doi.org/10.1155/2014/230382

19. Jena P, Pradhan AK (2011) Solution to directional relaying for double circuit line. In: Proceedings of international conference on energy, automation and signal. Bhubaneswar

20. Biswal M, Pati BB, Pradhan AK (2013) Directional relaying for double circuit line with series compensation. IET Gener Transm Distrib 7(4):405-413. https://doi.org/10.1049/iet-gtd.2012.0602

21. Idoniboyeobu D, Wokoma B (2017) Fault classification in doublecircuit transmission lines based on the hierarchical temporal memory. Am J Eng Res 6:301-306

22. Kumar R, Koley E, Yadav A, Thoke AS (2014) Fault classification of phase to phase fault in six phase transmission line using Haar wavelet and ANN. In: Proceedings of International Conference on Signal Processing and Integrated Network. Noida, pp 5-8

23. Elkalashy NI, Kawady TA, Khater WM (2016) Unsynchronized fault-location technique for double-circuit transmission systems independent of line parameters. IEEE Trans Power Deliv 31:1591-1600

24. Kang N, Liao Y (2013) Double-circuit transmission-line fault location. IEEE Trans Power Deliv 28:1040-1047

25. Yadav A, Swetapadma A (2015) A single ended directional fault section identifier and fault locator for double circuit transmission lines using combined wavelet and ANN approach. Electr Power Energy Syst 69:27-33

26. Papakostas GA, Tsougenis ED, Koulouriotis DE (2016) Fuzzy knowledge-based adaptive image water marking by the method of moments. Complex Intell Syst 2(3):205-220
27. Jamm BR, Pushpak Pati P, Patra SK, Mahapatra KK (2016) FPGA implementation of rule optimization for stand-alone tunable fuzzy logic controller using GA. Complex Intell Syst 2(2):83-98

28. Sharifi E, Mazinan AH (2018) On transient stability of multimachine power systems through Takagi-Sugeno fuzzy-based sliding mode control approach. Complex Intell Syst 4:171-179

29. Sertaç SA, Koçak O, Kamberli E, Koçum C (2007) Design and construction of a labview based temperature controller with using fuzzy logic

30. Chinthamani B, Rajeena Mol PT, Kamini KP, Sughashini KR (2012) Fuzzy based control using Labview for MISO temperature process. Int J Res Eng Technol 1(2):108-114

31. Ponce P, Ramirez Figueroa FD (2010) Intelligent control systems with LabVIEWTM. https://doi.org/10.1007/978-1-84882-684-7

32. Roy U, Ransai B, Roy G (2015) Design and performance of PID and fuzzy logic controller for thermal process using LabVIEW 1. Int J Electron Commun Technol 6(1)

33. Naresh Kumar A, Chakravarthy M (2019) Fuzzy inference system based distance estimation approach for multi location and transforming phase to ground faults in transmission line. Int J Comput Intell Syst 11(1):757-769

34. Naresh Kumar A, Sanjay Ch, Chakravarthy M (2019) Fuzzy inference system-based solution to locate the cross-country faults in parallel transmission lines. Int J Electr Eng Educ. https://doi.org/ 10.1177/0020720919830905

35. Naresh Kumar A, Sanjay Ch, Chakravarthy M (2019) Six phase transmission line protection against open conductor, phase to ground and simultaneous faults using fuzzy inference system. Int J Comput Intell Stud 8(3):245-267

36. Kumar P, Jamil M, Thomas MS, Moinuddin (1999) Fuzzy approach to fault classification for transmission line protection. In: Proceedings of IEEE Region 10 Conference Multimedia Technology for Asia-Pacific Information Infrastructure. Cheju Island

37. Mishra PK, Yadav A (2020) A single ended fuzzy based directional relaying scheme for transmission line compensated by fixed series capacitor. In: Proceedings of advances in intelligent systems and computing. Springer, Cham, pp 749-759

38. Naresh Kumar A, Sanjay Ch, Chakravarthy M (2019) Mamdani fuzzy expert system based directional relaying approach for sixphase transmission line. Int $\mathrm{J}$ Interact Multimedia Artif Intell. https://doi.org/10.9781/ijimai.2019.06.002

Publisher's Note Springer Nature remains neutral with regard to jurisdictional claims in published maps and institutional affiliations. 